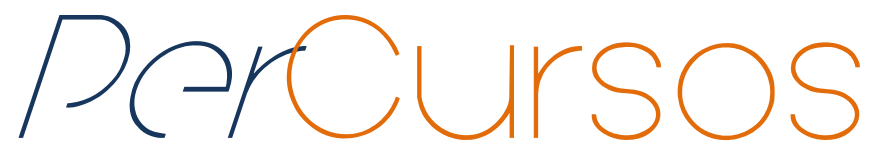

\title{
Estágio em educação infantil: formação compartilhada entre estagiários e professores em serviço?
}

\begin{abstract}
Resumo
O presente artigo pretende discutir a possibilidade de o estágio em docência na educação infantil se converter em momento de formação inicial e continuada, por meio de parceria entre universidade e rede municipal de ensino. Apresenta o debate instalado no campo dos estudos sobre educação infantil e sobre formação docente e relata a experiência da proposta de estágio em educação infantil do curso de Pedagogia da UFPR, apontando desafios que ainda permanecem para uma formação mais adequada dos profissionais que trabalham com crianças pequenas.
\end{abstract}

Palavras-chave: Estágio. Educação Infantil. Formação de Professores.

\section{Adriane Knoblauch}

Doutora em Educação.

Professora adjunta do

Departamento de Teoria e

Prática de Ensino da Universidade Federal do Paraná adrianeknoblauch@gmail.com

\section{Catarina de Souza Moro}

Doutora em Educação.

Professora adjunta do

Departamento de Teoria e

Prática de Ensino da

Universidade Federal do Paraná

moro.catarina@gmail.com

\section{Para citar este artigo:}

KNOBLAUCH, Adriane. MORO, Catarina de Souza. Estágio em educação infantil: formação compartilhada entre estagiários e professores em serviço?. Revista PerCursos. Florianópolis, v. 14, n.26, jan./jun. 2013. p. $87-107$.

\section{DOI: $10.5965 / 198472421426201387$}

http://dx.doi.org/10.5965/198472461426201387 


\title{
Stage in children education: training shared between stagers and teachers at work?
}

\begin{abstract}
This article aims to discuss the possibility that the stage in teaching in children education becomes a moment of initial and continued training, by means of a partnership between university and city schools. It presents the debate established in the field of the studies on children education and teaching training, and it shows the experience of the conception of stage in children education in the UFPR course of Education, indicating challenges that still remain to a more adequate training for the professionals who work with children.
\end{abstract}

Keywords: Stage. Children Education. Teachers Training. 


\section{Introdução}

A educação infantil, como campo de estudos, conta atualmente com um extenso acervo de literatura acadêmica. Contudo, a questão da prática pedagógica e do estágio da formação inicial, particularmente, ainda tem uma tímida expressão em forma de livros publicados. Em uma rápida busca em dois importantes meios de divulgação científica da área educacional, os anais da Anped e o banco de teses da Capes, constatou-se que, desde 2006, apenas seis trabalhos foram apresentados nas reuniões anuais da Anped com foco na formação, inicial ou continuada, para docência na educação infantil. No que se refere especificamente ao estágio na formação inicial para docência na educação infantil, no banco de teses da Capes foram encontrados apenas três trabalhos no período analisado ${ }^{1}$.

As professoras Luciana Esmeralda Ostetto e Ana Lúcia Goulart de Faria são as autoras que se dispuseram a reunir em livro algumas discussões e reflexões relativas aos conhecimentos e práticas dos professores em formação.

Muitas vezes, na forma de relatos de estágio, encontramos, nas suas obras, temas como: propostas e fazeres pedagógicos com diferentes grupos etários, inclusive com bebês e, entre profissionais, crianças e famílias; construção de interações em oposição à lógica adultocêntrica, baseada na escuta, na afetividade e no respeito às diferenças; coresponsabilidade das instituições de educação infantil e das universidades na formação de novos professores/educadores. Ou seja, relatos voltados à especificidade da educação para crianças pequenas, de caráter coletivo, em instituições educativas na esfera pública e que se concretizam em práticas pedagógicas para formar o cidadão desde sua inserção nesses contextos (FARIA, 2011; OSTETTO, 2008; LEITE e OSTETTO, 2004).

O objetivo deste texto é apresentar o debate instalado no campo dos estudos sobre educação infantil e sobre formação docente, bem como relatar a proposta de

\footnotetext{
1 O recorte a partir do ano de 2006 foi feito tendo em vista a aprovação das Diretrizes Curriculares Nacionais para o curso de Pedagogia, que definiram tal curso como o locus para a formação do docente para a Educação Infantil, como será discutido mais adiante. A busca nos anais da Anped ocorreu no GT Educação da Criança de o a 6 anos e no GT Formação de Professores. No banco de teses da Capes, a busca ocorreu por meio de palavras-chave, tais como: formação docente ou formação de professores, estágio curricular, educação infantil, a partir da opção "todas as palavras".
} 
estágio em educação infantil desenvolvida pela UFPR, destacando os desafios que ainda merecem ser enfrentados para a formação de qualidade dos profissionais da educação infantil, quer no âmbito da formação inicial, como no da formação continuada.

\section{1) Formação do profissional da educação infantil}

Desde há muito tempo, o debate no campo da educação infantil aponta para a necessidade de uma formação específica para os profissionais ${ }^{2}$ da educação infantil que trabalharão com as crianças pequenas. Esta necessidade se justifica na medida em que a formação inicial e continuada desses profissionais na primeira etapa da Educação Básica nacional constitui necessidade e desafio ainda prementes no Brasil, conforme atestam vários estudos e pesquisas na área e documentos oficiais do Ministério da Educação (CAMPOS et al., 2011; GODOI, 2010; MEC/SEB; UNESCO, 2009; CARVALHO e PEREIRA, 2008; CAMPOS, 2006; CORREA, 2003). Segundo tais estudos, a educação infantil tem revelado qualidade bastante inferior à adequada ao atendimento às crianças até os seis anos. Entre os fatores responsáveis por essa situação, encontra-se, certamente, a da formação insuficiente.

Vale destacar que, no Brasil, o movimento em torno da defesa dos direitos das crianças, dentre eles o direito à educação de qualidade, exerceu forte influência no processo de elaboração da Constituição de 1988. Pela primeira vez uma constituição brasileira reconheceu à criança pequena o direito à educação, definindo o Estado como responsável pela garantia no atendimento a creches e pré-escolas. No entanto, o princípio da descentralização, posto na Constituição, que transferiu para os municípios a responsabilidade financeira pelo referido atendimento, acabou, contraditoriamente, dificultando a conversão do direito assegurado no papel para direito de fato, tendo em vista a dificuldade de muitos municípios (FÓRUM CATARINENSE DE EDUCAÇÃO INFANTIL, 2002; CAMPOS, FÜLLGRAF, WIGGERS, 2006).

\footnotetext{
2 Usaremos indiscriminadamente os termos "profissionais da educação infantil" e "professores" para nos referir a todos aqueles que acompanham e desenvolvem o trabalho com as turmas de crianças nessa etapa educacional, pois sabemos que há uma diversidade de nomenclaturas e também de funções entre diferentes sistemas de ensino.
} 
Esta mesma contradição permanece na LDBEN 9394/96; mas o fato de a educação infantil ser considerada a primeira etapa da Educação Básica e, portanto, compor o sistema de ensino, possibilitou uma migração positiva dos programas meramente assistencialistas para projetos educativos que não dissociam o cuidado da educação. Além disso, ao indicar a formação de professores para a Educação Básica no âmbito da educação superior, ainda que admita a modalidade Normal como formação mínima, a LDBEN exige do profissional da educação infantil tal formação.

Num primeiro momento, duas instituições assumiram a responsabilidade por essa formação: os institutos superiores de educação, com o curso Normal Superior, e as universidades, com o curso de Pedagogia. A polêmica entre essas duas instâncias não será tratada aqui, tendo em vista os limites deste artigo. Ressalte-se, porém, que, a partir da promulgação das Diretrizes Nacionais para o Curso de Pedagogia, por meio da resolução CNE/CP 1/2006, o curso de Pedagogia foi definido como o locus privilegiado de formação do profissional da educação infantil e dos anos iniciais do ensino fundamental, apontando a docência como base para a formação do pedagogo.

No entanto, a educação infantil continua sendo a etapa para a qual as referências profissionais não estão devidamente adequadas e consolidadas, sendo ainda associadas à condição feminina, à maternagem, ao cuidado e socialização da criança (KRAMER, 2005). Estamos, assim, diante do desafio da construção de um novo grupo profissional, que requer a constituição de novos significados pelos envolvidos na educação das crianças pequenas.

Kishimoto (1999) argumenta que desde 1930 alguns cursos de Pedagogia já vinham ofertando a formação desse profissional, mas sempre como experiências isoladas e esparsas. Assim, é recente o fato de que a universidade passe a ter que discutir em seu interior as questões específicas da fralda, da chupeta, do choro, do faz-de-conta, das múltiplas linguagens, enfim, de questões próprias a quem trabalha com a criança pequena. Tal fato suscita, por um lado, a desconfiança por parte de alguns colegas, professores universitários, da real necessidade dessa discussão no interior da universidade, o que se traduz em menor apoio aos trabalhos que envolvem tais questões e, até mesmo, a dificuldade de contratação de novos professores para essa área. Por 
outro lado, para os que compreendem a necessidade dessa discussão e formação, há o empenho em construir propostas de trabalho que possam, efetivamente, formar um bom profissional em educação infantil.

Nessa última direção, vale lembrar que a formação do profissional da educação infantil deve estar em consonância com uma concepção de infância e com uma proposta de currículo apropriada. Tais especificidades estão explicitadas nas novas Diretrizes Curriculares Nacionais para a Educação Infantil (DCNEI), instituídas pela Resolução CNE/CEB $n^{\circ}$ 5, de dezembro de 2009 e discutidas no Parecer CNE/CEB $n^{\circ} 20$, de novembro do mesmo ano. Tais diretrizes resultaram de um amplo processo de discussão entre especialistas e dirigentes da área e definem a concepção e o currículo da educação infantil nacional. Em linhas gerais, o documento evidencia uma concepção de infância, na qual a(s) criança(s) é (são):

sujeito histórico e de direitos que, nas interações, relações e práticas cotidianas que vivencia, constrói sua identidade pessoal e coletiva, brinca, imagina, fantasia, deseja, aprende, observa, experimenta, narra, questiona e constrói sentidos sobre a natureza e a sociedade, produzindo cultura (BRASIL, 2009, p.1).

Em decorrência disso, as orientações para o trabalho pedagógico a ser realizado nas instituições de educação infantil, conforme as diretrizes atuais, primam pela articulação entre:

as experiências e os saberes das crianças com os conhecimentos que fazem parte do patrimônio cultural, artístico, científico e tecnológico da sociedade por meio de práticas planejadas e permanentemente avaliadas que estruturam o cotidiano das instituições (OLIVEIRA, 2010, p. 4).

A fim de garantir sua implementação, é fundamental aos profissionais de educação infantil ter a formação, inicial e/ou continuada, baseada na mesma concepção e que sua prática pedagógica seja orientada pelo currículo explicitado nas DCNEI.

Nessa mesma linha, Campos, Fülgraff e Wiggers (2006) destacam, na análise que fizeram sobre a produção de pesquisas acadêmicas referentes ao atendimento na educação infantil, que um dos principais problemas que interferem sobremaneira na qualidade dessa etapa de ensino diz respeito à formação de seus professores. Segundo as autoras, as pesquisas indicam que mesmo as profissionais que receberam formação em 
nível médio ou superior não receberam a qualificação necessária ao trabalho com a criança pequena, especialmente as que são atendidas em tempo integral nas creches. As autoras apontam, então, para uma inadequação de muitos cursos que pretendem formar o profissional da educação infantil.

Verifica-se, assim, mesmo entre os habilitados em Pedagogia, a necessidade de cursos de formação mais específica. Pode-se tomar como exemplo a enorme demanda por cursos de especialização em Educação Infantil observada nos Planos de Ação Articulada - PAR -, encaminhados ao MEC entre 2008 e 2011. Essa atingiu a casa de 19.771 professores, que deveriam ser atendidos naquele período.

Para responder a tal demanda, a Secretaria da Educação Básica do MEC (SEB), por meio de uma ação articulada entre a Coordenação Geral de Educação Infantil (Coedi) e a Diretoria de Políticas de Formação, Materiais Didáticos e de Tecnologias para Educação Básica/Coordenação Geral de Formação de Professores (CGFORM), em parceria com várias universidades federais, passou a ofertar, em 2009, o Curso de Especialização em Educação Infantil. Este constitui uma das principais ações da política nacional de formação para a educação infantil, que inclui também o Programa de Formação Inicial, em nível médio, modalidade Normal, para professores em exercício na Educação Infantil Proinfantil -, realizado entre os anos de 2005 a 2011 e os Cursos de Extensão Universitária de professores da Educação Infantil. A oferta da especialização teve início em 2010, com a adesão de 13 universidades e um total de 2.955 professores matriculados. A implementação foi sendo acompanhada pelo MEC, na intenção de privilegiar a troca de experiências e a construção coletiva, de forma a constituir-se uma rede entre as instituições formadoras e o ministério. Desse acompanhamento, propôs-se uma revisão, que culminou no Projeto do Curso de Especialização em Docência na Educação Infantil, a ser implementado em todas as universidades parceiras para a oferta a partir de 2011. A inclusão do termo "docência" no nome do curso teve o objetivo de explicitar seu foco, bem como o público-alvo prioritário - docentes de redes públicas municipais (BRASIL, 2011).

Entende-se que a inclusão da formação inicial e continuada para os professores da educação infantil como responsabilidade da Secretaria de Educação Básica (SEB) do 
Ministério da Educação (MEC), em parceria com as universidades federais e as secretarias municipais de Educação, indica o quanto a especificidade formativa para a educação infantil está na pauta nacional, requerendo tratamento de política pública.

No que se refere à formação inicial, dentre os componentes curriculares dos cursos de Pedagogia para formação de professores para educação infantil, o momento do estágio curricular pode ser converter numa importante ferramenta de reflexão sobre as atuais práticas e construção de novas, mais adequadas à concepção de criança defendida pelas DCNEI. Assim, é possível que o estágio se converta num processo de formação inicial de futuros professores, mas, também, de formação continuada dos professores que já estão em serviço, desde que haja uma forte parceria firmada entre universidades e redes municipais de ensino e que esse processo seja baseado em componentes de reflexão sobre a prática. Teceremos a seguir, neste sentido, algumas considerações sobre formação de professores. Em seguida, apresentaremos a forma como o estágio em educação infantil vem sendo desenvolvido com os estudantes de Pedagogia da UFPR, os problemas e avanços sentidos, bem como a necessidade de estreitar relações com as redes municipais na direção de uma formação mais compartilhada.

\section{2) Algumas orientações sobre formação de professores}

A defesa da formação de um professor com mais autonomia, capaz de refletir sobre seu trabalho cotidiano, não é recente. É possível afirmar que pode ser encontrada nos escritos de Dewey, mas ganha um novo impulso, ainda que redimensionado, nos anos de 1980 , tendo em vista o processo de redemocratização em diversas partes do mundo.

Segundo Pérez Gómez (2000), não há como dissociar a concepção de formação de professores de uma concepção mais ampla sobre a função social do ensino e da escola. Para o autor, há quatro perspectivas que se desenvolveram ao longo dos anos. A primeira é o que ele denomina de "perspectiva acadêmica", para a qual o ensino é um processo de transmissão de conhecimento e o professor deve ser um especialista no conteúdo que irá transmitir. Sua formação, então, deverá estar vinculada ao domínio de tais conteúdos. Tal 
perspectiva, por isso, concebe a formação docente de forma essencialmente teórica e desconsidera a existência de algum conhecimento que derive da prática profissional.

Decorrente de uma concepção tecnológica de atividade profissional, a “perspectiva técnica” se propôs dar um status mais científico à formação docente. Para esta perspectiva, ainda segundo Pérez Gómez (2000), o professor é visto como um técnico que domina e aplica o conhecimento científico produzido por outros. Assim, de acordo com a racionalidade técnica, sua atividade é apenas instrumental. Os problemas do ensino seriam superados mediante a aplicação rigorosa das técnicas criadas por outros profissionais. Restaria aos professores o conhecimento de tais técnicas para sua perfeita aplicação. Tal perspectiva defende, então, uma subordinação deste aos demais profissionais e a atividade prática é reduzida a mera atividade instrumental. Nessa perspectiva, para a formação docente bastaria o conhecimento das técnicas e um momento para sua aplicação, ou seja, o estágio.

Além de negar qualquer espaço de autonomia aos professores, tal perspectiva possui uma visão empobrecida de ensino e de formação docente, ao considerá-la apenas como uma questão técnica, desconsiderando a dimensão ético-política que, inevitavelmente, povoa as decisões de ordem mais técnica a serem tomadas tanto no nível do ensino quanto no da formação de professores. Este é um dos pilares dos críticos da perspectiva técnica, que ganhou destaque especialmente com os trabalhos de Donald Schön, ao cunhar os conceitos de profissional reflexivo e epistemologia da prática.

Ainda segundo Pérez Gómez (2000), a perspectiva de Schön, em conjunto com outros autores, ainda que com nuances diferençadas, é enquadrada na "perspectiva prática", que concebe a formação como aprendizagem a partir da prática, por meio de um enfoque reflexivo sobre a ação. Na opinião de Pérez Gómez, esta visão também se empobrece ao enfatizar demasiadamente a prática e o conhecimento tácito do professor, em detrimento de questões teóricas e mais amplas, o que, ao longo do tempo, pode tornar a "reflexão" dos professores insensível aos problemas cotidianos, que, num processo de reificação da prática cotidiana, podem passar a ser vistos como normais, o que naturalmente poderá conduzir à manutenção de práticas conservadoras. 
Como alternativa a essas três perspectivas, Pérez Gómez acrescenta ainda a “perspectiva de reflexão na prática para a reconstrução social”, que concebe o ensino como uma atividade crítica e o professor, como um profissional autônomo. Desta forma, sua prática não é meramente técnica, mas o elemento de reflexão não vem desarticulado de uma sólida formação teórica. Assim, tanto a formação como a atuação profissional devem estar baseadas em processos de pesquisa.

Com diferenças conceituais, tanto o que ficou conhecido como a perspectiva do professor reflexivo, como a do professor pesquisador, passou a povoar o discurso acadêmico e também político, a partir dos anos de 1980, com forte ênfase na década de 1990. A título de ilustração, alguns trabalhos analisaram os impactos desse novo discurso no ambiente brasileiro. Lelis (2001) advoga que houve uma mudança no discurso pedagógico sobre formação de professores, de modo que tais perspectivas constituíram um novo "idioma pedagógico", que ocupou o lugar da perspectiva anterior, que defendia a formação de professores centrada na pedagogia dos conteúdos. Para a autora, se a ênfase anterior era colocada nos conteúdos, a desse novo idioma passou a centrar-se na prática. Mesmo considerando interessantes os argumentos a favor de um tipo de conhecimento que se constrói na prática e que não é mera decorrência dos conteúdos acadêmicos e científicos aprendidos nos cursos de formação inicial - próprios do segundo idioma pedagógico -, a autora afirma haver desafios para o campo da pesquisa em formação de professores de forma a não ser necessária a defesa de um praticismo, nem, portanto, a de relativizar o papel da teoria.

Marin (2006), ao cotejar as diferentes propostas sobre o professor pesquisador com resultados de diversas pesquisas sobre atuação e formação docente, considera arriscado propor que o professor se torne um pesquisador de sua própria prática. Isso porque, segundo a autora, a pesquisa exige um encadeamento de ações que vão além da reflexão. Frente a tal exigência, ela se pergunta como formar professores pesquisadores considerando que muitos professores saem de seus cursos de formação com sérias fragilidades no que se refere ao domínio dos conteúdos que ensinarão e também ao domínio dos aspectos relativos às questões pedagógicas que envolvem seu trabalho. Defende, por isso, Desta forma, que os professores sejam inicialmente envolvidos em 
processos de pesquisa, considerando, a partir de Beillerot (2001), que fazer pesquisa é diferente de ser pesquisador. Sugere, ainda, que tais processos sejam rigorosamente acompanhados e avaliados por pesquisadores da área para que consigam as condições para o exercício efetivo dessa atividade.

Diante do exposto, consideramos que a reflexão faz parte do ofício docente, mas que precisa estar constantemente articulada com os fundamentos teóricos, para que não se perca na rotinização do trabalho docente. Assim, defendemos que deve fazer parte desse processo reflexivo a atitude de pesquisa e não propriamente a pesquisa em si. Ou seja, o trabalho do professor e a do pesquisador são trabalhos distintos, tendo em vista o rigor com que cada um deve ser desenvolvido. Mas há elementos da pesquisa que são úteis para uma reflexão mais densa que o professor pode fazer sobre seu trabalho, tais como, a problematização, a comparação, o aprofundamento teórico, entre outros. É à incorporação desses elementos que denominamos atitude de pesquisa.

Frente a essas considerações, apresentamos a proposta para o estágio em educação infantil do curso de Pedagogia da UFPR, bem como a avaliação que fizemos do seu desenvolvimento e a necessidade de radicalização de alguns princípios inicialmente definidos.

\section{3) A proposta para o estágio em docência na educação infantil do curso de pedagogia da}

\section{UFPR e a radicalização de alguns princípios}

O curso de Pedagogia da UFPR é voltado à formação do professor desde 1996, quando passou a formar, a partir da concepção de "pedagogo unitário", um profissional para atuar tanto na esfera da gestão, quanto da docência nos anos iniciais do ensino fundamental e das disciplinas pedagógicas do ensino médio, conforme currículo aprovado pelo Conselho de Ensino, Pesquisa e Extensão (Cepe) da UFPR, por meio da resolução 15/96. Um processo de avaliação desse currículo culminou no ajuste curricular, oficializado pela resolução 26/99 do referido conselho. Por meio desse ajuste, o curso passou a habilitar também para a docência na educação infantil, embora sem acréscimo de novas disciplinas voltadas a esse nível de ensino. 
Sentiu-se, porém, a necessidade de nova alteração desse currículo por meio de um processo de discussões que teve início a partir do ano de 2002, por um lado, em virtude de avaliações internas envolvendo professores e alunos, as quais apontavam para a necessidade de melhorar a formação para a docência, entre outros aspectos; por outro, em virtude do atendimento às resoluções do Conselho Nacional de Educação (CNE).

A Resolução do CNE/CP n. 01/2006 institui as Diretrizes Curriculares Nacionais para o Curso de Pedagogia, em nível de licenciatura. Segundo tal resolução, o Curso de Pedagogia é responsável pela formação do professor de educação infantil e dos anos iniciais do ensino fundamental, além de se comprometer com a formação da gestão e da pesquisa. Frente a essas demandas, a opção do atual currículo do Curso de Pedagogia da UFPR, aprovado pela Resolução 30/08 do Conselho de Ensino, Pesquisa e Extensão (CepeUFPR), se deve à indissociabilidade entre os eixos da docência, da organização e gestão dos processos formativos e da pesquisa, o que pode ser complementado com a ideia da docência como base para a formação do pedagogo, defendida ao longo dos anos 1980 por amplos setores da academia e sistematizada pela Anfope (SCHEIBE, 2007).

A estrutura curricular do curso, seguindo orientações de Scheibe (2000), prevê três contextos em torno dos quais as disciplinas se agrupam: contexto histórico e sociocultural; contexto da educação básica; contexto do exercício profissional: saber acadêmico, pesquisa e prática educativa. Ao lado das demais disciplinas que tratam da educação infantil, direta ou indiretamente, em suas ementas, há o Estágio em Docência na Educação Infantil, uma disciplina de 120 horas, para cuja orientação há professoras especificamente concursadas, embora em número ainda insuficiente. Os dados aqui analisados se referem à forma de organização dessa disciplina em parceria com os centros municipais de educação infantil (CMEls) da cidade de Curitiba. Aprovado em 2008, o atual currículo passou a vigorar em 2009, de modo que as turmas de estágio em educação infantil foram ofertadas em 2011 e 2012, atendendo, em média, 150 estudantes de Pedagogia em cada ano, distribuídos em aproximadamente 50 CMEls. 
A proposta elaborada pelas professoras ${ }^{3}$ da área responsável por esse estágio prevê que os estudantes ${ }^{4}$ de Pedagogia frequentem as instituições no sentido de desenvolver tarefas de observação, monitoria e desenvolvimento de projetos pedagógicos ao longo de um semestre letivo. Para isso, os estudantes devem frequentar os CMEIs dois dias por semana, ao longo de um semestre letivo. Em alguns momentos, há reuniões com grupos maiores de estudantes para aprofundamento teórico, discussão das problemáticas sentidas e elaboração de aulas e projetos pedagógicos a serem desenvolvidos. Ao final do processo, espera-se dos estudantes a elaboração de um artigo científico no qual problematizem alguns aspectos que mais chamaram sua atenção durante as observações e/ou o desenvolvimento dos projetos pedagógicos. A fim de garantir um maior aprofundamento na análise das culturas infantis, das crianças reais e dos contextos coletivos de educação, indica-se aos estagiários que acompanhem exclusivamente uma turma ao longo de todo o estágio e que o trabalho de pesquisa/reflexão ocorra conjuntamente com os professores e demais profissionais docentes da referida turma, tendo em vista que consideramos relevante, já na atividade de estágio, investigar e buscar compreender o que caracteriza sua prática profissional na educação infantil, justamente em função do que requer o trabalho educativo com crianças pequenas. São diversos os elementos que interagem no processo de se tornar professor. A natureza da profissão docente é complexa e é necessário compreendê-la em suas características próprias, analisando a atividade concreta dos profissionais seus contextos cotidianos de trabalho, perante a complexidade e multiplicidade de situações envolvidas na prática docente.

Neste sentido, essa proposta foi elaborada para garantir um maior aprofundamento das discussões sobre a formação e atuação do profissional da educação infantil de forma a reconhecer as singularidades da pequena infância e dar-lhes atendimento, reconhecendo a criança como um interlocutor com direito à educação, ao cuidado, à brincadeira e às múltiplas linguagens num processo de ampliação de saberes e

\footnotetext{
3 A proposta foi elaborada de forma coletiva entre as professoras responsáveis pela disciplina naquele momento: Adriane Knoblauch, Catarina de Souza Moro, Leziany Silveira Daniel e Marilia Andrade Torales.

4 Usaremos os termos estudantes ou estagiários para nos referir aos graduandos de Pedagogia, em processo de formação inicial e que realizam o estágio em docência na educação infantil.
} 
interações (FARIA, 2011; KRAMER, 2009; OSTETTO, 2008; FARIA, 2007; LEITE e OSTETTO, 2004; CRAIDY e KAERCHER, 2001) e, ao mesmo tempo, garantir um processo de análise em relação às práticas existentes e à construção de novas práticas por meio da relação entre teoria e prática, na construção da práxis (PIMENTA e LIMA, 2004; PIMENTA, 2001; PÉREZ GÓMEZ, 2000).

Vale destacar, ainda, que cada professor orientador ${ }^{5}$ de estágio atende, em média, a uma turma de 15 estagiários por semestre. Nos dias em que os estagiários estão nos CMEIs, tais professores fazem visitas sistemáticas aos locais de estágio para acompanhar o trabalho que vem sendo desenvolvido, bem como para auxiliar os estagiários na observação e problematização das práticas desenvolvidas, discutindo diferentes aspectos pertinentes àqueles contextos educativos.

É possível indicar que um dos avanços dessa proposta, sentido pelos professores orientadores e pelos estagiários, foi o fato de o estágio ocorrer em dois dias na semana. Isto permitiu maior vinculação com as crianças e com os profissionais da educação infantil em tempo menor, o que possibilitou uma inserção mais qualitativa dos estudantes no interior da instituição. Mas, talvez, o maior avanço tenha sido o de o estagiário perceber a dinâmica do trabalho dos CMEls, podendo acompanhar em continuidade, com hiatos menores e de forma mais atenta, o trabalho pedagógico desenvolvido na instituição.

Além disso, em meio ao desenvolvimento do estágio, percebemos algumas dificuldades reveladoras da complexidade dos diferentes contextos de educação da pequena infância nos quais os estagiários interagiram:

- houve limitações para as possibilidades de discussão, trocas de experiência e busca de reflexão teórica, no próprio contexto dos CMEls entre o estagiário, o professor/educador/pedagogo da unidade e o professor orientador da UFPR;

- a disponibilidade das equipes dos CMEls em relação ao estágio são muito distintas, referindo o quanto o aceite do estagiário ou do grupo de estágio não significa, necessariamente, abertura para intercâmbios e orientações;

\footnotetext{
5 O termo professor orientador se refere aos professores da universidade em que são responsáveis pela disciplina de estágio em docência.
} 
- o fato de o professor orientador de estágio ter alunos distribuídos em um número grande de CMEls compromete a presença quinzenal ou, ainda melhor, semanal, em cada unidade e atrapalha a continuidade das observações e discussões com os estudantes;

- a falta ou a frágil fundamentação teórica referente à educação infantil por parte dos estagiários quando iniciam a disciplina;

- a dificuldade do estagiário em acompanhar a elaboração do planejamento pela equipe da turma que ele acompanhou, às vezes pela incompatibilidade de dias em que isso acontecia e, outras vezes, pela não-ocorrência desse planejamento em função da falta de pessoal para assumir a turma no momento previsto para esse trabalho.

Dessa forma, alguns pontos merecem nossa revisão para o aperfeiçoamento dessa proposta. Talvez, nosso maior desafio seja o de estreitar ainda mais os laços com a rede municipal, especialmente com as instituições em que é feito o estágio. Isso porque, como afirmado acima, a formação para a docência tem inúmeras complexidades e, particularmente, na educação infantil, que nem sempre tem sido adequada, de modo que incorre na observação de práticas cotidianas contraditórias com o discurso, que, por isso, vão de encontro à formação teórico-acadêmica a partir da qual os estudantes travam discussões e buscam compreender, no sentido de se fazer professores de crianças pequenas. Em outros casos, a instituição concedia apenas a possibilidade de observação das práticas, ou permitia escassos momentos de intervenção. Em nossa avaliação, isso ocorreu porque a parceria oferecida por nós não foi, de fato, efetivada. Nestes casos, o estagiário e o professor orientador eram vistos como intrusos pela instituição e não como parceiros.

Outro ponto a destacar é que, em nenhum momento, o artigo científico foi construído de forma coletiva entre estagiário e os profissionais responsáveis pela turma de crianças. Diante do acúmulo de trabalho que acomete tais profissionais, a escrita desse artigo foi vista como mais uma entre tantas tarefas. Como, em nenhum momento, houve a obrigatoriedade disso, optaram por não fazê-lo. 
De todo modo, a escrita do artigo, ainda que sem a participação desses profissionais, foi positiva para os estudantes, pois foi um momento importante para a reflexão deles sobre o que vivenciaram ou observaram durante o estágio. Avaliamos que tal escrita caminha na direção por nós anteriormente defendida, que era a de desenvolver nos estagiários uma atitude de pesquisa, importante para a docência.

A experiência relatada por Oliveira-Formosinho (2002) é inspiradora, especialmente por radicalizar os princípios por nós propostos. A autora defende um modelo ecológico de supervisão no estágio, considerando que, além do estagiário, do professor de educação infantil e do orientador de estágio, outros elementos interferem na formação do futuro professor, sobretudo os do ambiente da instituição e de sua interrelação com o contexto social mais amplo. No âmbito do "Projeto Infância", a autora destaca a necessidade de formação das "educadoras cooperantes" 6 para que entendam que possuem um papel importante no processo de formação dos estagiários. Esta formação, além das questões relativas ao trabalho de orientação do estágio, deve envolver também a discussão de um referencial teórico comum relativo à infância e a modelos curriculares de qualidade para todos os envolvidos no processo do estágio: professores orientadores da universidade, professores cooperantes e estagiários. A perspectiva da autora é que todos os envolvidos são agentes de investigação-ação, o que resultaria em formação continuada para todos os participantes do processo.

Nessa mesma direção, outro grupo de professoras formadoras e professoras de educação da infância (de crianças entre três e cinco anos), também em Portugal (CRAVEIRO et al., 2010), discutem, a partir de uma pesquisa por elas realizada, aspectos fundamentais relativos à iniciação na prática profissional.

Para as autoras, "a instituição formadora tem um papel fundamental na escolha das instituições de estágio que proporcionam aos alunos", com vistas a contextos nos quais os educadores cooperantes já desenvolvem "práticas de grande qualidade" e nos

\footnotetext{
${ }^{6}$ O termo educadores cooperantes é relativo aos profissionais que atuam diretamente com as crianças nas turmas dos diferentes contextos educativos, que, no caso de Portugal, são "educadores de infância" que recebem estagiários e cooperam e sua formação, profissionais formados em instituições de ensino superior.
} 
quais se pode intervir no sentido do "melhoramento progressivo das condições da qualidade da prática dos mesmos". A perspectiva do grupo de autoras considera que o profissional da instituição de educação infantil que recebe estagiários está numa "relação triangulada entre a função de educar as crianças, ser orientador dos estudantes e ser modelo de actuação da prática" (CRAVEIRO et al., 2010, p. 42).

Neste sentido, a parte relatada da pesquisa (CRAVEIRO et al., 2010) buscou identificar a qualidade da ação dos educadores, bem como dos contextos e processos proporcionados pelos profissionais às crianças. A título de conclusão e encaminhamentos, as autoras ressaltam que é fundamental definir propostas de formação/intervenção junto aos educadores cooperantes, a fim de oportunizar o estudo e a reflexão acerca dos conceitos e das práticas considerados imprescindíveis ao trabalho cotidiano com as crianças, relativos: à sensibilidade do adulto ao bem-estar infantil; à forma de intervir e ao conteúdo das intervenções em relação à aprendizagem; ao grau de autonomia dado às crianças e à forma de gerir conflitos entre elas e lidar com regras e diferentes reações comportamentais das crianças e, ainda, oportunizar a participação em projetos de atuação, experimentação e troca de experiências que contribuirão para o reconhecimento crítico acerca do tipo de atuação, considerando a "relação triangulada" que eles deverão assumir e desenvolver.

Desta forma, o estágio se converteria em um momento de formação inicial para os estagiários, mas também em processos de formação continuada para as profissionais da educação infantil que já estão em serviço, a partir de uma reconceitualização do papel da supervisão. Nas palavras de Oliveira-Formosinho:

A supervisão reconceptualizada desenvolve-se e reconstrói-se, coloca-se em papel de apoio e não de inspeção, de escuta e não de definição prévia, de colaboração activa em metas acordadas através de contratualização, de envolvimento na acção educativa quotidiana (através de pesquisa cooperada), de experimentação reflectida através da acção que procura responder ao problema identificado. [...] uma supervisão contextualizada, porque centrada nos problemas identificados nos contextos de trabalho e desenvolvida nos contextos organizacionais que poderão resolver esses mesmos problemas... (2002, p. 12-13). 
Este é, então, o grande desafio a ser assumido por aqueles que compreendem a necessidade de melhorar a formação inicial e continuada dos que trabalham com as crianças pequenas, considerando a importância do desenvolvimento de uma atitude de pesquisa para o desenvolvimento do ofício docente.

\section{Referências bibliográficas}

BEILLEROT, J. A “pesquisa”: esboço de uma análise. In: ANDRÉ, M. (Org.). O papel da pesquisa na formação e na prática dos professores. Campinas: Papirus, 2000. pp. 71-90.

BRASIL. Resolução CNE/CP nº 01/2006. Institui Diretrizes Curriculares Nacionais para o Curso de Pedagogia, Licenciatura. Brasília: MEC/CNE, 2006.

. Parecer CNE/CEB n 20/2009. Revisão das Diretrizes Curriculares Nacionais para a Educação Infantil. Brasília: MEC/CNE/CEB, 2009.

. Resolução CNE/CEB nº5/2009. Fixa as Diretrizes Curriculares Nacionais para a

Educação Infantil. Brasília: MEC/CNE/CEB, 2009.

. Projeto Básico para o Curso de Especialização em Docência na Educação Infantil. Não publicado. Brasília: MEC, 2011.

CAMPOS, M. M. et al. A qualidade da educação infantil: um estudo em seis capitais Brasileiras. In: Cadernos de Pesquisa, v.41, n. 142, 2011. p. 20-54.

. Consulta sobre qualidade da Educação infantil: relatório técnico final. São Paulo: Fundação Carlos Chagas, 2006.

;; FÜLGRAFF, J. e WIGGERS, V. A qualidade da educação infantil brasileira: alguns resultados de pesquisa. In: Cadernos de Pesquisa, v. 36, n. 127, 2006. p. 87-128,

CARVALHO, A. M.; PEREIRA, A. S. Qualidade em ambientes de um programa de educação infantil pública. In: Psicologia: Teoria e Pesquisa, v. 24, n. 3, 2008. p. 269-277.

CORREA, B. C. Considerações sobre qualidade na educação infantil. In: Cadernos de Pesquisa. n. 119, 2003. p. 85-112. 
CRAIDY, C.; KAERCHER, G. (Orgs.) Educação Infantil: pra que te quero? Porto Alegre: ArtMed, 2001.

CRAVEIRO, C. et al. Estudo sobre a qualidade da prática pedagógica em instituições cooperantes de estágio. In: Cadernos de Educação de Infância. n. 89, p. 42-47, jan./abr. 2010.

FARIA, A. L. G. de. (Org.) Culturas infantis em creches e pré-escolas - estágio e pesquisa. Campinas: Autores Associados, 2011.

(Org.). O coletivo infantil em creches e pré-escolas: falares e saberes. São Paulo: Cortez, 2007.

FÓRUM CATARINENSE DE EDUCAÇÃO INFANTIL. A infância no papel é de papel: as duas faces da nova LDBEN. In: MOVIMENTO INTERFÓRUNS DE EDUCAÇÃO INFANTIL NO BRASIL. Educação infantil: construindo o presente. Campo Grande: Editora UFMS, 2002, pp. 29-42.

GODOI, E. G. Avaliação na Creche: o disciplinamento dos corpos e a transgressão das crianças. In: Educação: Teoria e Prática, v. 20, n. 35, jul./dez. 2010. p. 21-37.

KISHIMOTO, T. M. Política de formação profissional para educação infantil: Pedagogia e Normal Superior. In: Educação \& Sociedade, n. 68, 1999. p. 61-79.

KRAMER, S. (Org.). Retratos de um desafio: crianças e adultos na educação infantil. São Paulo: Ática, 2009.

KRAMER, S. Formação de profissionais de educação infantil: questões e tensões. In: MACHADO, M. L. (rg.). Encontros e desencontros em Educação Infantil. São Paulo: Cortez, 2005, p. 117-132.

LEITE, M. I. e OSTETTO, L. E. (Orgs.). Arte, Infância e Formação de Professores - autoria e transgressão. Campinas: Papirus, 2004.

LELIS, I. A. Do ensino de conteúdos aos saberes do professor: mudança de idioma pedagógico? In: Educação \& Sociedade, n. 74, 2001. p. 43-58. 
MARIN, A. J. Professores, pesquisa e formação. In: SILVA, A. M. M. et al. (Orgs.). Educação formal e não formal, processos formativos e saberes pedagógicos: desafios para a inclusão social. Recife: Edições Bagaço, 2006, pp. 329-348.

PÉREZ GÓMEZ, A. I. A função e formação do professor/a no ensino para a compreensão: diferentes perspectivas. In: GIMENO SACRISTÁN, J. e PÉREZ GÓMEZ, A. I. Compreender e transformar o ensino. Porto Alegre: Artes Médicas, 2000, pp. 353-379.

MEC/SEB; UNESCO. Política de educação infantil no Brasil: Relatório de avaliação. Ministério da Educação/Secretaria de Educação Básica. Brasília: MEC, SEB; Unesco, 2009.

OLIVEIRA-FORMOSINHO, J. (Org.). A supervisão na formação de professores I: da sala à escola. Porto: Porto Editora, 2002.

OLIVEIRA, Z. de M. R. de. O Currículo na Educação Infantil: o que propõem as novas diretrizes nacionais? Impresso não publicado, disponível na página do MEC para consulta pública. Brasília: MEC, 2010.

OSTETTO, L. E. (Org.) Educação Infantil - Saberes e fazeres da formação de professores. Campinas: Papirus, 2008.

PIMENTA, S. G. O Estágio na Formação de Professores: unidade teoria e prática? São Paulo: Cortez, 2001.

e LIMA, Ma do S. Estágio e Docência. SP: Cortez, 2004.

SCHEIBE, L. Formação e identidade do pedagogo no Brasil. In: Vera Maria Candau (Org.). Ensinar e aprender: sujeitos, saberes e pesquisa. Rio de Janeiro: DP\&A editores, 2000, pp. 922.

. Diretrizes Curriculares para o curso de Pedagogia: trajetória longa e inconclusa. In: Cadernos de Pesquisa, v. 37, n. 130, jan./abr. 2007. p. 43-62, 
